\title{
On the effect of phase transformations on saline ice compliance
}

\author{
L. R. McKitTrick AND R. L. BRown \\ Civil Engineering Department, Montana State University, Bozeman, Montana 59717, U.S.A.
}

\begin{abstract}
To obtain a better understanding of the compliance of saline ice, we developed a simple conceptual model of a process that presumably takes place in saline ice. Using elastic models, we assessed the role that phase transformations might play when brine is sealed into small cells during crystal growth. Cooling of a sealed brine cell, leading to the precipitation of ice, provides a mechanism for the accumulation of "large" localized stresses. Based on our analysis, this mechanism has the potential to be a significant source for the nucleation of dislocations, and can conceivably make a significant contribution to the greater compliance (softness) of saline ice relative to non-saline ice.

The results of this model are consistent with the observation that laboratory-grown saline crystals sometimes display extensive differences in mechanical behavior that appear to be due to variations in the growth and storage conditions experienced by the crystals.
\end{abstract}

\section{PURPOSE}

Our goal in this paper is to further the understanding of the mechanical behavior of saline ice relative to non-saline ("pure") ice. In particular, we focus on the role of phase transformations as a source of variation in the the compliance of saline $(\mathrm{NaCl})$ single ice crystals. In the process, we evaluate the likelihood that phase transformations can have a significant effect on the compliance of saline ice. At the same time, we hope to provide a firm

\footnotetext{
${ }^{1}$ A single crystal may be defined as a specimen that grows solely from one nucleus, so that no part of the specimen is more than $5^{\circ}$ from the mean orientation (Winegard, 1964, ch. XII). Using Kawamura's (1986) method, a seed crystal is constructed from a single crystal with a vertical $c$ axis. To construct the seed crystal, the original crystal is sliced into plates such that the crystalline $a$ axis is perpendicular to the plane of the plate, and the $c$ axis lies in the plane of the plate. The plates are placed side by side, aligning the $c$ axis of each plate. The plates are then "sintered" together to form a quasi-single crystal seed. Often there is a fine line of small randomly oriented crystals that develop at the interface between plates. These lines will sometimes extend into a specimen grown from the seed. If carefully applied, this approach yields specimens with crystal orientations within $3^{\circ}$ of the mean, except for small $(<1 \mathrm{~mm})$ crystals on the interface planes. The specimen is grown from as many as four nuclei (plates). Though we would expect the resulting specimen to behave structurally as a single crystal, it does not meet the definition of a single crystal; therefore, we refer to specimens grown by this technique as quasi-single crystals.
}

foundation for subsequent studies of phase transformations and how they affect dislocation nucleation in saline ice.

\section{INTRODUCTION}

To better our understanding of the behavior of saline ice relative to non-saline ice, we grew quasi-single crystals ${ }^{1}$ of saline and non-saline ice using the method developed by Kawamura (1986). The crystals were grown with a horizontal $c$ axis and a vertical $a$ axis and were typically $25 \mathrm{~cm}$ square and $20 \mathrm{~cm}$ deep. These large crystals were then cut into specimens $5 \mathrm{~cm}$ square and $22 \mathrm{~cm}$ long where the $c$ axis was oriented at $45^{\circ}$ relative to the long axis of the specimen. The specimens, both saline and non-saline, were compressed at a constant strain rate $\left(\dot{\varepsilon}=1 \times 10^{-6} \mathrm{~s}^{-1}\right)$. The averaged responses are shown (Fig. 1) in terms of shear stress resolved on the basal plane, at temperatures of $20^{\circ}$ and $-40^{\circ} \mathrm{C}$. Each curve represents the averaged response of two specimens after smoothing by a leastsquares technique (Savitzky and Golay, 1964).

Saline ice crystals typically are conceptualized as a bridged matrix of non-saline ice platelets with a regularly spaced system of brine cavities and possibly air bubbles interspersed throughout. With this conceptual model, one would expect saline ice to display a response similar to that of non-saline ice, though with somewhat lower macroscopic stresses; indeed there are such cases. For an example of such an analogous behavior, between saline and non-saline ice, consider the experimental results of Brown and Kawamura (1991).

Brown and Kawamura tested quasi-single crystals of saline ice that were not subjected to thermal cycling. Upon removal from the crystal-growth bath, their 


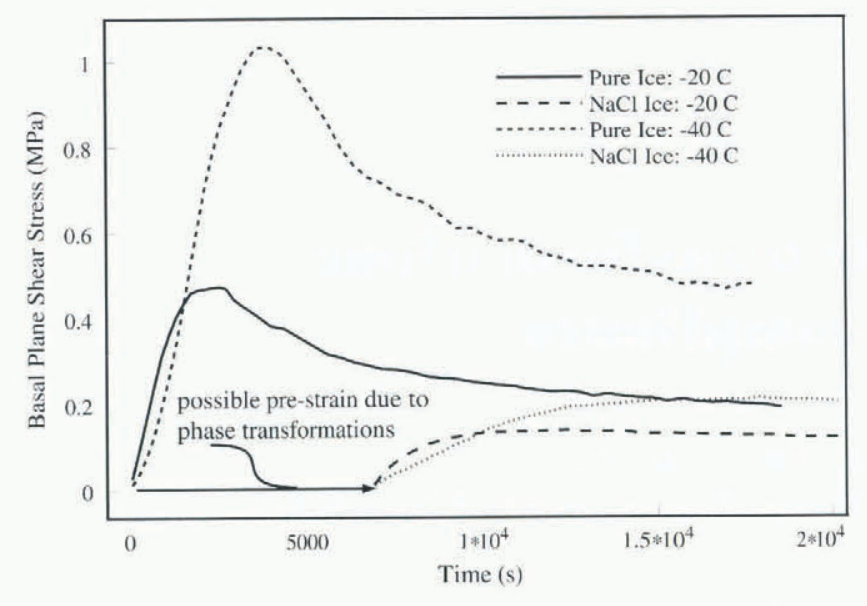

Fig. 1. Stress response for constant strain rate $(\dot{\epsilon}=$ $\left.1 \times 10^{-6} \mathrm{~s}^{-1}\right)$.

specimens were stored at $-11^{\circ} \mathrm{C}$, both during the period they were allowed to drain and after the time they were cut into specimens. During the entire period, the temperature variations were probably no more than $\pm 0.1^{\circ} \mathrm{C}$, since the specimens were stored inside insulated boxes stored inside a cold room which had temperature control to within $\pm 1^{\circ} \mathrm{C}$. Prior to testing, each specimen was slowly cooled to the test temperature.

In tests conducted at Montana State University (Fig. 1), a similar procedure was used, but the cold room had a larger temperature oscillation, and the test specimens were subjected to a very low thermal cycling between $-10^{\circ}$ and $20^{\circ} \mathrm{C}$ while they were stored. This cycling occurred when the cold-room temperature was slowly lowered over a period of approximately 1 month in order to grow new saline quasi-single crystals. The cyclic thermal loading may have affected the material ductility and elastic after-effect, if it resulted in cyclic inelastic deformation.

Typical models for the strength of sea ice (Anderson, 1958; Assur, 1958; Weeks and Assur, 1967; Michel, 1978; Weeks and Ackley, 1982) connect the reduction in strength of sea ice relative to non-saline ice using a function of brine content with models of the form

$$
\sigma^{\mathrm{S}}=c \sigma^{\mathrm{N}}\left[1-f\left(\phi^{\mathrm{S}}\right)\right]
$$

where $\sigma^{\mathrm{S}}$ and $\sigma^{\mathrm{N}}$ are the strength of saline ice and nonsaline ice, respectively, $\phi^{\mathrm{S}}$ is the brine content or porosity of the sea ice, and $c$ is a reduction coefficient and is commonly used to include stress concentration factors or other structural characteristics. But in Figure 1 it is clear that there are cases where saline ice does not display the peaked stress response or large yield drops that the nonsaline ice does. Models that use geometric reduction, in terms of porosity or brine content, to explain the reduced strength of saline ice do not explain the absence of a peaked stress response in saline crystals when such a response is lacking.

If we view the responses in Figure 1 in terms of dislocation theory, we might consider the peak stress in single crystals as the point where the energy level in the crystal is sufficient for the stable nucleation ${ }^{2}$ (multiplication) of dislocations. Two possible explanations exist for the lack of similarity between the two types of crystal responses. First, the saline ice crystal has a high mobiledislocation density before it is ever loaded in the test apparatus, and secondly, some internal mechanism plays a significant role in lowering the activation energy required for the nucleation of dislocations in the saline ice crystal. Here we consider phase transformations of brine in internal cells in saline crystals as a possible mechanism for the introduction of a high density of dislocations before the saline crystal is ever subjected to external mechanical loads.

\section{PHASE TRANSFORMATIONS}

We chose to pursue phase transformations as a factor in the behavior of saline ice since they seem likely to induce deformation in the saline ice crystal during growth or storage, so that any mechanical testing performed on test specimens is actually done on specimens which have been pre-deformed in the neighborhood of the brine cells. If this mechanism induces stress sufficient to produce local deformation well into the plastic regime, then, in the case of ice, softening will effectively occur without the necessity of external loads.

\section{Ice crystallization from brine}

As crystals of ice form in a brine solution, nearly all of the solute (salt, air, etc.) remains in solution (Weeks and Ackley, 1982, p. 4). As the crystals grow into the melt they form a series of parallel blade-like platelets about $0.5 \mathrm{~mm}$ thick. As growth proceeds, observers (Anderson and Weeks, 1958; Weeks and Ackley, 1982; Grenfell, 1983) report that the platelets thicken and bridges begin to form approximately $2.5 \mathrm{~cm}$ above the lower tip of the platelets. The bridging process between platelets develops around vertical columns of brine which might extend vertically through the entire crystal. As the ice cools further, the columns of brine collapse into arrays of nearly spherical or ellipsoidal brine cells. As the brine cells age, they have an increased tendency to take on an ellipsoidal geometry.

Utilizing this outline of crystal development, we assume that the ice crystal and trapped brine are stressfree immediately after the brine columns collapse into arrays of nearly spherical brine cells. Then the driving question becomes, what happens as the ice and brine are cooled further?

Here we will focus on the role of the phase transformation that brine, which is trapped in these cells, undergoes as the crystal temperature drops either during the growth stage or while in storage.

\section{Phase changes}

To quantify the phase changes, we will define the salinity

${ }^{2}$ The predominant source of dislocations in ice is typically thought to be the multiplication of pre-existing dislocations, in the sense first modeled by Johnston and Gilman (1960). We prefer to use the term nucleation in the sense that the source of nucleation is typically a preexisting dislocation. 
of the brine $\left(s^{\mathrm{B}}\right)$ by the non-dimensional form

$$
s^{\mathrm{B}}=\frac{m^{\mathrm{S}}}{m^{\mathrm{B}}}=\frac{\text { mass of salt }}{\text { mass of brine }} .
$$

To understand the relationship between the phases of brine and ice, consider the phase-diagram cartoon (Fig. 2) from Weeks and Ackley (1982). For a brine solution with a salinity of 0.035 , when the temperature drops to $-2{ }^{\circ} \mathrm{C}$, water precipitates out of the brine in the form of ice. If the brine is contained in a small closed system, then the transformation from water to ice implies that the mass of brine decreases significantly while the mass of salt in solution remains "constant"; thus the salinity of the brine increases. The increase in brine salinity requires a decrease in temperature before more ice can precipitate out. This process will continue until the brine reaches the eutectic point, at a salinity of 0.233 and a corresponding temperature of $-21.2^{\circ} \mathrm{C}$. Before the temperature of the brine can drop below the eutectic point, the brine solution must assume the solid form of sodium chloride dihydrate $\left(\mathrm{NaCl} \cdot 2 \mathrm{H}_{2} \mathrm{O}\right)$.

Phase transformations are dependent on changes in pressure and temperature (LaChapelle, 1968). That is, as pressure increases, the phase curve typically depresses. To keep the mathematical development relatively simple, we will assume that the phase change is independent of

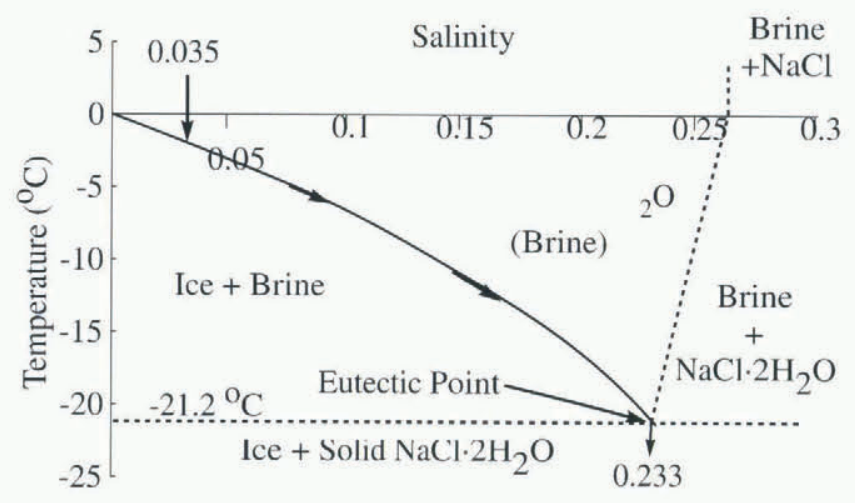

Fig. 2. Phase diagram for $\mathrm{H}_{2} \mathrm{O}$ and $\mathrm{NaCl}$.

pressure. Cox and Weeks (1975, table I) use the following third-order polynomial to model the phase relationship between the brine salinity $\left(s^{\mathrm{B}}\right)$ and the freezing/melting temperature $(T)$ :

$$
\begin{aligned}
s^{\mathrm{B}}=( & -17.573 T-0.381246 T^{2} \\
& \left.-3.28336 \times 10^{-3} T^{3}\right) \times 10^{-3}
\end{aligned}
$$

where the transformation temperature $(T)$ is in ${ }^{\circ} \mathrm{C}$. Their equation is based on a statistical fit of experimental data with a correlation coefficient of 0.999927 and a standard error equal to 0.4334 .

\section{Phase densities}

For brine density, we assume that pressure and temperature are independent variables and that temperature and salinity are directly correlated. For the stress-free density of brine $\left(\rho^{\mathrm{B}}\right)$, we use the approximation for sea brine given by Cox and Weeks (1983, equation 16),

$$
\rho^{\mathrm{B}}=\rho^{\mathrm{W}}\left(1+\frac{s^{\mathrm{B}}}{\zeta^{\mathrm{B}}}\right)
$$

where

$$
\zeta^{\mathrm{B}}=1.25
$$

and $\rho^{\mathrm{W}}$ is the density of water at $0^{\circ} \mathrm{C}$. For the density of non-saline ice $\left(\rho^{\mathrm{I}}\right)$, we use the approximation given by Pounder (1965, equation 29),

$$
\rho^{\mathrm{I}}=\rho_{0}{ }^{\mathrm{I}}\left(1-1.53 \times 10^{-4} T\right)
$$

where the temperature $T$ is in ${ }^{\circ} \mathrm{C}$ and $\rho_{0}{ }^{\mathrm{I}}$ represents the density of ice at $0^{\circ} \mathrm{C}$ with the value:

$$
\rho_{0}{ }^{\mathrm{I}}=916.8 \mathrm{~kg} \mathrm{~m}^{-3} \text {. }
$$

When the temperature of the brine drops below the eutectic point, and the brine takes on the solid form of sodium chloride dihydrate $\left(\mathrm{NaCl} \cdot 2 \mathrm{H}_{2} \mathrm{O}\right)$, the density of the solid is approximately $1630 \mathrm{~kg} \mathrm{~m}^{-3}$ (Weeks and Ackley, 1982, table I); comparing the density of this solid form with the density of brine (Equation (4)) at the eutectic point $\left(\rho_{\mathrm{e}}{ }^{\mathrm{B}}=1186 \mathrm{~kg} \mathrm{~m}^{-3}\right)$ implies that the brine contracts as it transforms into solid form. Given the nature of our query, we will not concern ourselves with temperatures below the eutectic point.

\section{VOLUMETRIC STRAIN (DUE TO PHASE TRANS- FORMATIONS)}

In this section, we consider the stress-free variations in the volume of the components contained in a brine cell due solely to phase transformations. To quantify the changes, we place an imaginary boundary around an arbitrary brine cell when it is first sealed or completely surrounded by ice but is yet "stress-free". We then consider the changes in component volumes (brine and ice), assuming components are unconstrained. This imaginary process is illustrated in Figure 3.

Our model of a brine cell consists of three distinct structural components. First is the ice external to the brine cell. Second is the brine trapped in the brine cell. Third is the ice that precipitates out of the brine to form an icy shell on the inside of the original brine cell. This precipitation continues as the temperature of the brine cell drops. Given the lower density of ice, as ice precipitates out, the total system must expand.

In this section, we are concerned only with the volume changes resulting from the two components on the interior of the original brine cell. Though Figure 3 illustrates polar or spherical geometry, the volume changes modeled in this section are independent of geometry.

\section{Notation}

For state variables, $m$ is mass, $s$ is salinity, $\rho$ is density, and $V$ is volume. For the components, the superscripts "S", "B", "I", and "W" designate salt, brine, precipitated ice, and non-saline water, respectively. Superscript "O" will identify combined components of the "original" 


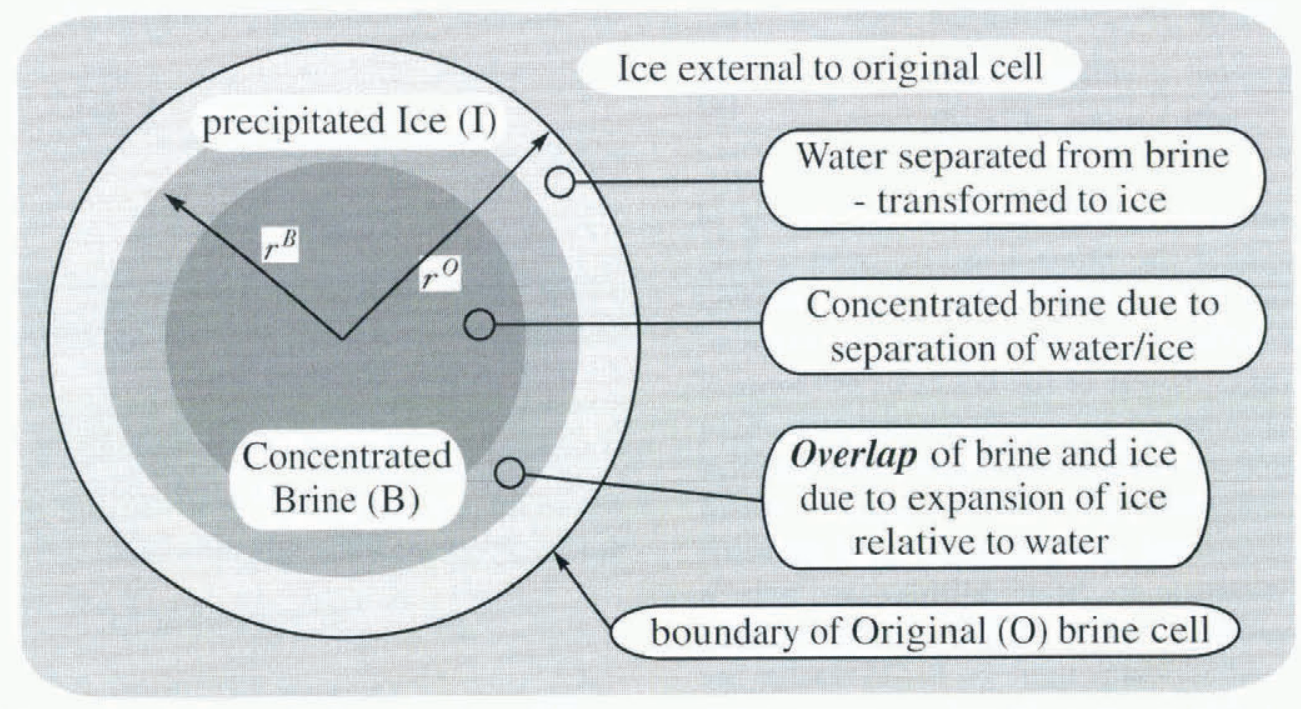

Fig. 3. Conceptual (spherical) model for a brine transformation.

brine system. Subscripts index the state; in particular, "o" denotes the initial state, and "T" denotes variations due to the phase transformation from brine to ice.

\section{Brine transformation volume}

Because the most significant volume changes hinge on the transformation from brine to ice, we will start by modelling the transformation volume of the brine $\left(V_{\mathrm{T}}{ }^{\mathrm{B}}\right)$.

Given the closed nature of a brine cell, the mass of salt contained in a cell remains constant. In addition, we will assume that all of the salt mass is retained within the brine to the extent that, upon freezing, ice rejects practically all of the salt. Based on experimental results (Weeks and Ackley, 1982, p. 4), this assumption is a good approximation for density calculations. Based on the preceding statements, we can write the following relation.

$$
m^{\mathrm{S}}=s_{\mathrm{o}}{ }^{\mathrm{B}} \rho_{\mathrm{o}}{ }^{\mathrm{B}} V_{\mathrm{o}}{ }^{\mathrm{B}}=s^{\mathrm{B}} \rho^{\mathrm{B}} V_{\mathrm{T}}{ }^{\mathrm{B}} \text {. }
$$

Rearranging terms, we can represent the transformation brine volume $\left(V_{\mathrm{T}}^{\mathrm{B}}\right)$ by

$$
V_{\mathrm{T}}{ }^{\mathrm{B}}=V_{\mathrm{o}}{ }^{\mathrm{B}}\left(\frac{s_{\mathrm{o}}{ }^{\mathrm{B}} \rho_{\mathrm{o}}{ }^{\mathrm{B}}}{s^{\mathrm{B}} \rho^{\mathrm{B}}}\right) \text {. }
$$

Representing the brine density as a function of salinity (Equation (4)), we can write

$$
\frac{V_{\mathrm{T}}{ }^{\mathrm{B}}}{V_{\mathrm{o}}{ }^{\mathrm{B}}}=\frac{s_{\mathrm{o}}{ }^{\mathrm{B}}\left(\zeta^{\mathrm{B}}+s_{\mathrm{o}}{ }^{\mathrm{B}}\right)}{s^{\mathrm{B}}\left(\zeta^{\mathrm{B}}+s^{\mathrm{B}}\right)} .
$$

If $T \leq T_{\mathrm{o}}$, then $\zeta^{\mathrm{B}}=1.25>0.233 \geq s^{\mathrm{B}} \geq s_{\mathrm{o}}{ }^{\mathrm{B}}$ implies the volume is approximately inversely proportional to the salinity and is related in a similar fashion to temperature. ${ }^{3}$

$$
\frac{\tilde{V}_{\mathrm{T}}^{\mathrm{B}}}{V_{\mathrm{o}}^{\mathrm{B}}} \approx \frac{s_{\mathrm{o}}^{\mathrm{B}}}{s^{\mathrm{B}}}
$$

The term $\tilde{V}_{\mathrm{T}}^{\mathrm{B}}$ indicates an approximation of the transformation brine volume $\left(V_{\mathrm{T}}^{\mathrm{B}}\right)$; this approximation emphasizes the relationship between the brine volume and the brine salinity. In essence, as the salinity increases, there is less and less brine volume for ice to precipitate from; therefore, the most significant changes should occur immediately after a sealed brine cell begins to cool.

\section{Differential changes for the total transformation volume}

We will describe the stress-free (transformation) volume of the brine cell $\left(V_{\mathrm{T}}{ }^{\mathrm{O}}\right)$ as the sum of the reduced brine volume $\left(V_{\mathrm{T}}^{\mathrm{B}}\right)$ and the precipitated ice volume $\left(V_{\mathrm{T}}^{\mathrm{I}}\right)$ :

$$
V_{\mathrm{T}}^{\mathrm{O}}=V_{\mathrm{T}}^{\mathrm{B}}+V_{\mathrm{T}}^{\mathrm{I}}=\frac{m^{\mathrm{B}}}{\rho^{\mathrm{B}}}+\frac{m^{\mathrm{I}}}{\rho^{\mathrm{I}}} .
$$

As indicated earlier, the superscript "O" denotes the original brine system. Here, after the temperature is lowered, the original system consists of the remaining brine and the ice that has precipitated out of the brine. Differentiating the preceding expression yields

$$
\mathrm{d} V_{\mathrm{T}}^{\mathrm{O}}=\frac{\mathrm{d} m^{\mathrm{B}}}{\rho^{\mathrm{B}}}-\frac{m^{\mathrm{B}} \mathrm{d} \rho^{\mathrm{B}}}{\left(\rho^{\mathrm{B}}\right)^{2}}+\frac{\mathrm{d} m^{\mathrm{I}}}{\rho^{\mathrm{I}}}-\frac{m^{\mathrm{I}} \mathrm{d} \rho^{\mathrm{I}}}{\left(\rho^{\mathrm{I}}\right)^{2}} .
$$

Considering the differential density change for brine, the stress-free brine density can be written as a function of temperature and salinity. We have chosen to express the density changes as a function of salinity, such that temperature effects are included implicitly (Equations (3) and (4)); thus

$$
\rho^{\mathrm{B}}=\rho^{\mathrm{W}}+\frac{\rho^{\mathrm{W}}}{\zeta^{\mathrm{B}}} s^{\mathrm{B}},
$$

3 The relative difference in these two approximations (Relations (10) and (11)) can be written as

$$
\frac{V_{\mathrm{T}}{ }^{\mathrm{B}}-\tilde{V}_{\mathrm{T}}{ }^{\mathrm{B}}}{V_{\mathrm{T}}{ }^{\mathrm{B}}}=\frac{s_{\mathrm{O}}{ }^{\mathrm{B}}-s^{\mathrm{B}}}{\zeta^{\mathrm{B}}+s_{\mathrm{o}}{ }^{\mathrm{B}}} .
$$

If $s_{\mathrm{o}}{ }^{\mathrm{B}}=0.035$, this difference reaches a maximum of $15 \%$, near the eutectic point. 
and differentiating yields

$$
\mathrm{d} \rho^{\mathrm{B}}=\frac{\rho^{\mathrm{W}}}{\zeta^{\mathrm{B}}} \mathrm{d} s^{\mathrm{B}} .
$$

Considering the differential density change for ice, all but a very small amount of salt is rejected from ice so that salinity can be neglected. Also, since we are concerned only with temperature changes on the order of $20^{\circ} \mathrm{C}$, density changes will be small so that the density differential may be neglected. ${ }^{4}$

Returning to the expression for the differential volume change (Equation (13)), substituting for the brine density differential (Equation (15)), recalling $V_{\mathrm{T}}^{\mathrm{B}}=m^{\mathrm{B}} / \rho^{\mathrm{B}}$, and allowing the density differential for the precipitated ice to vanish, we have

$$
\mathrm{d} V_{\mathrm{T}}^{\mathrm{O}} \approx \frac{\mathrm{d} m^{\mathrm{B}}}{\rho^{\mathrm{B}}}+\frac{\mathrm{d} m^{\mathrm{I}}}{\rho^{\mathrm{I}}}-V_{\mathrm{T}}^{\mathrm{B}} \frac{\rho^{\mathrm{W}} \mathrm{d} s^{\mathrm{B}}}{\rho^{\mathrm{B}} \zeta^{\mathrm{B}}} .
$$

Focusing on the first two terms in the differential volume expression, the mass of the brine in the original system can be written as

$$
m_{\mathrm{o}}{ }^{\mathrm{B}}=m^{\mathrm{B}}+m^{\mathrm{I}}
$$

because the mass of precipitated ice in the original system is zero $\left(m_{\mathrm{o}}{ }^{\mathrm{I}}=0\right)$. Differentiating the preceding mass relation, we have

$$
\mathrm{d} m^{\mathrm{I}}=-\mathrm{d} m^{\mathrm{B}} .
$$

Substituting into the volumetric differential (Equation (16)) and simplifying,

$$
\mathrm{d} V_{\mathrm{T}}{ }^{\mathrm{O}}=-\frac{\mathrm{d} m^{\mathrm{B}}}{\rho^{\mathrm{B}}}\left(\frac{\rho^{\mathrm{B}}}{\rho^{\mathrm{I}}}-1\right)-V_{\mathrm{T}}^{\mathrm{B}} \frac{\rho^{\mathrm{W}} \mathrm{d} s^{\mathrm{B}}}{\rho^{\mathrm{B}} \zeta^{\mathrm{B}}} .
$$

To make this equation more useful, we will express the first term in terms of salinity rather than mass. Using the definition of brine salinity (Equation (2)), the brine mass can be written as:

$$
m^{\mathrm{B}}=\frac{m^{\mathrm{S}}}{s^{\mathrm{B}}} .
$$

Recalling that the salt mass $\left(m^{\mathrm{S}}\right)$ is constant, differentiating, and substituting $m^{\mathrm{S}}=m^{\mathrm{B}} s^{\mathrm{B}}$ and $m^{\mathrm{B}}=\rho^{\mathrm{B}} V_{\mathrm{T}}^{\mathrm{B}}$, we have

$$
\mathrm{d} m^{\mathrm{B}}=-\frac{m^{\mathrm{B}}}{s^{\mathrm{B}}} \mathrm{d} s^{\mathrm{B}}=-\frac{\rho^{\mathrm{B}} V_{\mathrm{T}}^{\mathrm{B}}}{s^{\mathrm{B}}} \mathrm{d} s^{\mathrm{B}} .
$$

Returning to the volumetric differential Equation (19)) and substituting for $\mathrm{d}^{\mathrm{B}}$ (Equation (21)), we

${ }^{4}$ Differentiating Equation (6), setting $\mathrm{d} \rho^{\mathrm{I}}=\Delta \rho^{\mathrm{I}}$ and $\mathrm{d} T=\Delta T=-20^{\circ} \mathrm{C}$,

$$
\Delta \rho^{\mathrm{I}}=\rho_{0}{ }^{\mathrm{I}}\left(-1.53 \times 10^{-4} \Delta T\right) \approx 0.003 \rho_{0}{ }^{\mathrm{I}}
$$

implies that the density of the precipitated ice changes less than $0.3 \%$ for temperature changes less than $20^{\circ} \mathrm{C}$. have

$$
\frac{\mathrm{d} V_{\mathrm{T}}^{\mathrm{O}}}{V_{\mathrm{T}}^{\mathrm{B}}}=\left[\left(\frac{\rho^{\mathrm{B}}}{\rho^{\mathrm{I}}}-1\right) \frac{1}{s^{\mathrm{B}}}-\frac{\rho^{\mathrm{W}}}{\rho^{\mathrm{B}}} \frac{1}{\zeta^{\mathrm{B}}}\right] \mathrm{d} s^{\mathrm{B}} .
$$

Substituting for $\rho^{\mathrm{B}}$ as a function of salinity (Equation (4)), we have

$$
\mathrm{d} V_{\mathrm{T}}^{\mathrm{O}}=V_{\mathrm{T}}^{\mathrm{B}}\left[\frac{\rho^{\mathrm{W}}}{\rho^{\mathrm{I}} \zeta^{\mathrm{B}}}+\xi \frac{1}{s^{\mathrm{B}}}-\frac{1}{s^{\mathrm{B}}+\zeta^{\mathrm{B}}}\right] \mathrm{d} s^{\mathrm{B}}
$$

where

$$
\xi=\left(\frac{\rho^{\mathrm{W}}}{\rho^{\mathrm{I}}}-1\right) .
$$

This differential relation gives us a measure of the increasing interference between the two phases, i.e. brine and ice.

\section{Strain function}

Consider the use of the preceding volumetric differential (Equation (23)) as a strain measure. The total volume differential $\left(\mathrm{d} V_{\mathrm{T}}{ }^{\mathrm{O}}\right)$ gives us a measure of the total volume change of the original brine-cell contents under stress-free conditions. If we take the brine volume as a reference volume, then it appears that all of the expansion is taking place in the brine. Integrating this strain measure between the initial state and the current state yields a measure of the total strain $\left(e_{\mathrm{T}}^{\mathrm{B}}\right)$ relative to the brine volume, ${ }^{5}$ i.e.,

$$
e_{\mathrm{T}}^{\mathrm{B}}\left(V, V_{\mathrm{o}}\right)=\int_{V_{0}=V_{0}^{\mathrm{B}}}^{V} \frac{\mathrm{d} V_{\mathrm{T}}^{\mathrm{O}}}{V_{\mathrm{T}}^{\mathrm{B}}} .
$$

Making the change of variables from volumetric measures to salinity (Equation (23)), the strain can be described by

$$
\begin{aligned}
e_{T}{ }^{\mathrm{B}}\left(s^{\mathrm{B}}, s_{\mathrm{o}}{ }^{\mathrm{B}}\right) & =\int_{s_{0}^{\mathrm{B}}}^{s^{\mathrm{B}}}\left[\frac{\rho^{\mathrm{W}}}{\rho^{\mathrm{I}} \zeta^{\mathrm{B}}}+\xi \frac{1}{s^{\mathrm{B}}}-\frac{1}{s^{\mathrm{B}}+\zeta^{\mathrm{B}}}\right] \mathrm{d} s^{\mathrm{B}} \\
& =\left[\frac{\rho^{\mathrm{W}}}{\rho^{\mathrm{I}}}\left(\frac{s^{\mathrm{B}}-s_{\mathrm{o}}{ }^{\mathrm{B}}}{\zeta^{\mathrm{B}}}\right)+\ln \left(\frac{s^{\mathrm{B}}}{s_{\mathrm{o}}{ }^{\mathrm{B}}}\right)^{\xi}\left(\frac{\zeta^{\mathrm{B}}+s_{\mathrm{o}}{ }^{\mathrm{B}}}{\zeta^{\mathrm{B}}+s^{\mathrm{B}}}\right)\right]
\end{aligned}
$$

where $\xi$ is defined in Equation (23).

To obtain the volumetric strain measure as a function of temperature, replace the brine salinity $s^{\mathrm{B}}$ with a function of temperature, $s^{\mathrm{B}}(T)$ defined in Equation (3),

\footnotetext{
${ }^{5}$ In some cases it may be appropriate to define the reference volume as the sum of the brine volume and the expansion volume (volume increase due to the transformation from water to ice). This altered reference volume $\left(\dot{V}_{\mathrm{T}}^{\mathrm{B}}\right.$ ) can be defined by

$$
\dot{V}_{\mathrm{T}}^{\mathrm{B}}=V_{\mathrm{T}}^{\mathrm{O}}-\frac{m^{\mathrm{I}}}{\rho^{\mathrm{W}}}=V_{\mathrm{T}}^{\mathrm{B}}+\xi V_{\mathrm{T}}^{\mathrm{I}} .
$$

The strain using this definition is $20 \%$ less by the time the eutectic point is reached. We will continue to define the strain relative to the brine volume (Equation (26)) as we will find it more accurate for our pressure analysis.
} 
so that:

$$
e_{T}^{\mathrm{B}}=e_{T}^{\mathrm{B}}\left(s^{\mathrm{B}}, s_{\mathrm{o}}^{\mathrm{B}}\right)=e_{T}^{\mathrm{B}}\left[s^{\mathrm{B}}(T), s^{\mathrm{B}}\left(T_{\mathrm{o}}\right)\right] .
$$

To study the behavior of this strain function, recall $\zeta^{\mathrm{B}}=1.25$ as defined in Equation (4), let the specific gravity of ice $\left(\rho^{\mathrm{I}} / \rho^{\mathrm{W}}\right)$ equal 0.917 , and let the initial temperature $T_{0}=-2 \mathrm{C}$ (for the present, we assume the trapped brine starts with a salinity of 0.035 , though it will probably be higher); the resulting volumetric strain profile is shown in Figure 4.

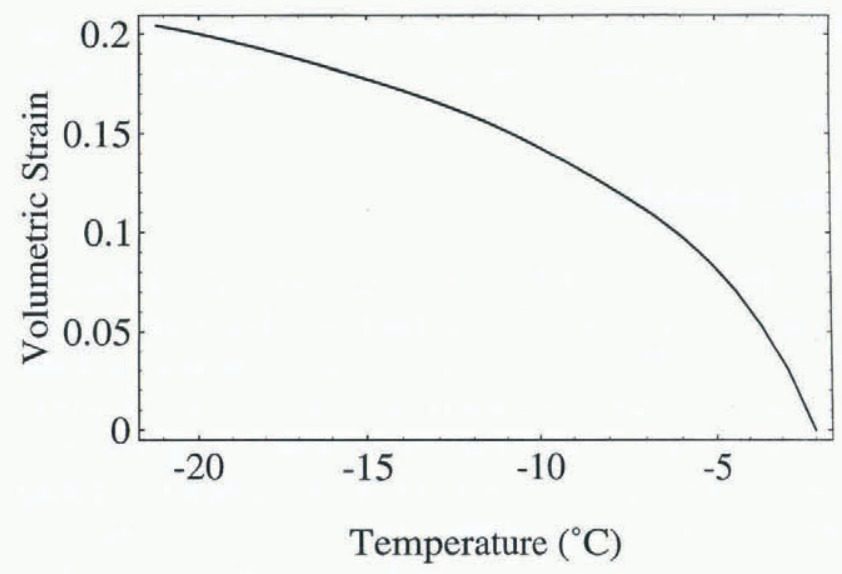

Fig. 4. Volumetric transformation strain $\left(e_{\mathrm{T}}^{\mathrm{B}}\right)$.

\section{Polynomial approximations}

For numerical models, polynomials are much easier to work with. By choosing an initial temperature $\left(T_{\mathrm{o}}\right)$, corresponding to the initial salinity of the brine $\left(s_{0}\right.$ B $)$ immediately after the cell is sealed, we can approximate the volumetric strain using a fifth-order polynomial. For the initial temperature, we chose to let $T_{\mathrm{o}}=-2^{\circ} \mathrm{C}$.

To model the entire range between the initial temperature and the eutectic temperature $\left(T_{\mathrm{e}}=\right.$ $-21.2^{\circ} \mathrm{C}$ ), we used Chebychev polynomials as a basis, ${ }^{6}$ obtaining a polynomial approximation with a maximum offset of $1.24 \times 10^{-3}$, which occurred at $T_{\mathrm{o}}$. form

The polynomial approximation takes the following

$$
\tilde{e}_{\mathrm{T}}^{\mathrm{B}}=-\left(\sum_{j=0}^{5} \alpha_{j} T^{j}\right) \times 10^{-6}
$$

with the coefficients listed in Table 1 , where $T$ is in ${ }^{\circ} \mathrm{C}$.

${ }^{6}$ For the Chebychev approximation $\left(\tilde{e}_{\mathrm{T}}{ }^{\mathrm{B}}\right)$, we used the least-squares technique (Atkinson, 1989, §4.5). Starting with a basis of the Chebychev polynomials $\left(\tau_{j}\right)$, we have

$\tilde{e}_{\mathrm{T}}^{\mathrm{B}}(x)=\frac{c_{\mathrm{o}}}{2}+\sum_{j=1}^{4} c_{j} \tau_{j}(x) \quad c_{j}=\frac{2}{\pi} \int_{-1}^{1} \frac{e_{T}^{\mathrm{B}}(x) \tau_{j}(x) \mathrm{d} x}{\sqrt{1-x^{2}}}$

where $x$ is related to the temperature $(T)$ by $T=\left[\left(T_{\mathrm{o}}-T_{\mathrm{e}}\right) x+\left(T_{\mathrm{o}}+T_{\mathrm{e}}\right)\right] / 2$. The resulting approximation can then be rearranged into standard form (Equation (28)).
In some cases, it is advantageous to model the transformation expansion as thermal expansion. If large (logarithmic) strain components are used, the volumetric strain can be represented by

$$
e_{\mathrm{T}}^{\mathrm{B}}=3 \alpha \Delta T
$$

where $\alpha$ is the coefficient of thermal (transformation) expansion and $\Delta T=T-T_{\mathrm{o}}$ is the temperature difference between the initial stress-free temperature $\left(T_{\mathrm{o}}\right)$ and the brine temperature $(T)$. To approximate the expansion coefficient, recall the expansion is "zero" at the initial temperature $\left(T_{\mathrm{o}}\right)$. Coincidentally, for the polynomial approximation (Equation (28)), there is a root $\left(\tilde{T}_{0}\right)$ near $T_{\mathrm{o}}$; therefore we can factor $\Delta T=\left(T-\tilde{T}_{\mathrm{o}}\right)$ out of the polynomial model $\left(\alpha=\tilde{e}_{\mathrm{T}}{ }^{\mathrm{B}} /(3 \Delta T)\right)$, so that

$$
\alpha\left[{ }^{\circ} \mathrm{C}^{-1}\right]=-\left(\sum_{j=0}^{4} \beta_{j} T^{j}\right) \times 10^{-6}
$$

for $T_{\mathrm{e}} \leq T \leq T_{\mathrm{o}}$ with the parameters given in Table 1 , where $T$ is in ${ }^{\circ} \mathrm{C}^{7}$

\section{Discussion}

Notice that the volumetric strain $\left(e_{\mathrm{T}}^{\mathrm{B}}\right)$ is larger than might be expected, if we considered a simple transition from water to ice. ${ }^{8}$ This discrepancy is due to the fact that we are considering the apparent strain in the brine, measuring the volumetric strain relative to the brine volume rather than the the total cell volume. Because the strain represented by $e_{\mathrm{T}}{ }^{\mathrm{B}}$ is not small, engineering strain measures do not make good approximations.

\section{PRESSURE VARIATIONS}

In this section, we use the volume changes modeled in the previous section to evaluate the build-up of hydrostatic pressure in the brine. Our primary interest is in the stress fields in the surrounding ice, but we will use the brine pressure as a boundary condition for the stresses in the ice.

For the pressure estimate itself, we combine a sequence of differentials to obtain a solution and explore the salinity temperature dependence of the pressure build-up in the brine cells. Our approach here is similar to one used by Picu and others $(1994, \S 1.2)$, though our results appear

$\overline{7 \text { To clarify the relationship between the two polynomial }}$ approximations, notice

$$
\sum_{j=0}^{5} \alpha_{j} T^{j}=3\left(T-T_{\mathrm{o}}\right) \sum_{j=0}^{4} \beta_{j} T^{j}
$$

${ }^{8}$ The volumetric strain resulting from a transition from water to ice can be simply modeled by

$$
\frac{\Delta V}{V}=\frac{\rho^{\mathrm{W}}-\rho^{\mathrm{I}}}{\rho^{\mathrm{I}}}=0.0905 \text {. }
$$


Table 1. Polynomial parameters

$$
\tilde{e}_{\mathrm{T}}{ }^{\mathrm{B}}
$$

$\alpha$

$\begin{array}{llll}\alpha_{0} & 98675.9 & \beta_{0} & 16714.8 \\ \alpha_{1} & 63399.2 & \beta_{1} & 2245.22 \\ \alpha_{2} & 7756.88 & \beta_{2} & 172.983 \\ \alpha_{3} & 558.147 & \beta_{3} & 6.63967 \\ \alpha_{4} & 20.5021 & \beta_{4} & 0.0987772 \\ \alpha_{5} & 0.296332 & \tilde{T}_{0}\left({ }^{\circ} \mathrm{C}\right) & -1.96783\end{array}$

to be significantly different. ${ }^{9}$

In the previous section, we considered the volume changes in the components by assuming the brine and precipitated ice were allowed to overlap (Fig. 3). In this section, we will enforce compatibility between the brine and ice as illustrated in Figure 5, allowing us to model the pressure that accumulates as ice precipitates from the brine.

To simplify the mathematics and yet maintain a reasonable representation of a typical brine cell, we will now assume the brine cell is spherical in shape and that the surrounding ice extends ad infinitum.

\section{Notation}

In addition to the notation of the previous section, the subscript "C" denotes components due to material constraints, and superscript "i" denotes parameters related to the brine/ice interface.

In particular, we let $r^{\mathrm{i}}$ represent the radius of the brine/ice interface and $P^{\mathrm{B}}$ represent the hydrostatic pressure in the brine and hence the pressure at the interface.

\section{Compatibility}

We start by enforcing compatibility at the interface between the precipitated ice (I) and the brine (B). The displacement for each side of the interface is divided into two components. The first expresses the displacement of the interface due to phase transformations, denoted by subscript " $T$ ". The second expresses the displacement of the interface due to the pressure at the interface, denoted by subscript "C". To satisfy compatibility, the total displacement differential must be the same for each side of

\footnotetext{
${ }^{9}$ Based on the inverse relationship between the brine volume and the brine salinity (Relation (11)), one would expect the slope of the pressure profile to decrease at the lower temperatures due to the decrease in the volume of brine available for the precipitation of ice. The pressure profile plotted by Picu and others (1994, fig. 3) displays an increasing slope at lower temperatures (higher salinities). Our differential relations are similar to those used by Picu and others; therefore, the lapse most likely occurred in the integration of the differential relations.
}

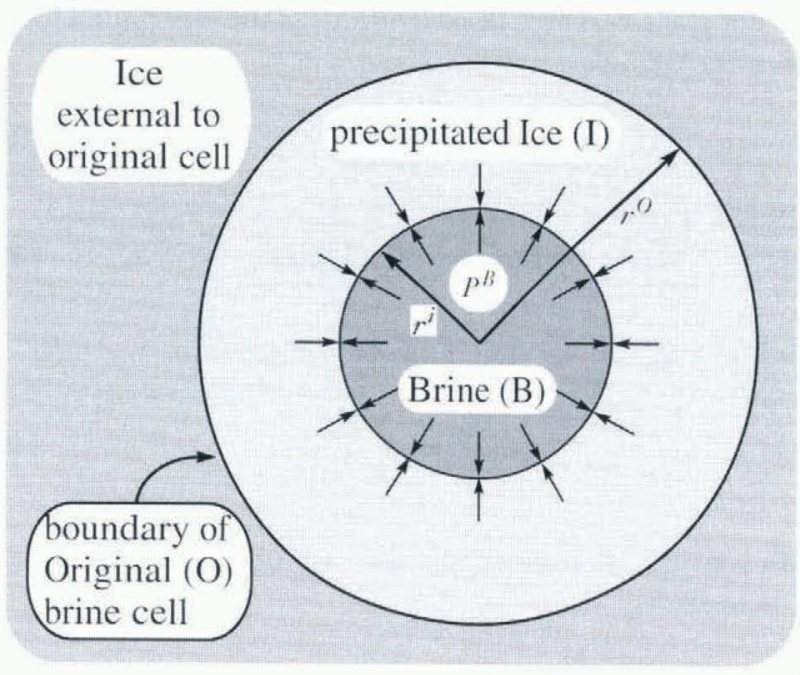

Fig. 5. Conceptual (spherical) model for a brine cell.

the interface:

$$
\mathrm{d} u_{\mathrm{T}}{ }^{\mathrm{I}}+\mathrm{d} u_{\mathrm{C}}{ }^{\mathrm{I}}=\mathrm{d} u_{\mathrm{T}}{ }^{\mathrm{B}}+\mathrm{d} u_{\mathrm{C}}{ }^{\mathrm{B}} .
$$

Using an elastic model for concentric spheres (Love, 1944, $\S 98$ ) and assuming the outer radius of the ice mass is very large with no external pressure, we arrive at the relation:

$$
\mathrm{d} u_{\mathrm{C}}{ }^{\mathrm{I}}=\frac{r^{\mathrm{i}} \mathrm{d} P^{\mathrm{B}}}{4 \mu^{\mathrm{I}}}
$$

for the radial displacement of the inner radius of the surrounding ice mass due to a brine pressure increment, $\mathrm{d} P^{\mathrm{B}}$.

For the stress-free displacement of the ice interface,

$$
V_{\mathrm{T}}^{\mathrm{I}}=V_{\mathrm{T}}^{\mathrm{O}}-\frac{4}{3} \pi\left(r^{\mathrm{i}}\right)^{3} .
$$

Because we are concerned with transformation displacement and the original cell is constrained by the surrounding ice, we assume the precipitation of ice results in displacement of the interface rather than changing the outer boundary $\left(\mathrm{d} V_{\mathrm{T}}^{\mathrm{I}}=0-4 \pi\left(r^{\mathrm{i}}\right)^{2} \mathrm{~d} u_{\mathrm{T}}^{\mathrm{I}}\right)$, so that

$$
\mathrm{d} u_{\mathrm{T}}^{\mathrm{I}}=-\frac{\mathrm{d} V_{\mathrm{T}}^{\mathrm{I}}}{4 \pi\left(r^{\mathrm{i}}\right)^{2}} .
$$

For the differential displacement of the brine interface resulting from the constraining forces of the surrounding ice

$$
\mathrm{d} V_{\mathrm{C}}{ }^{\mathrm{B}}=-\frac{V^{\mathrm{i}}}{K^{\mathrm{B}}} \mathrm{d} P^{\mathrm{B}}
$$

and in terms of the spherical geometry of our conceptual model, we can write

$$
4 \pi\left(r^{\mathrm{i}}\right)^{2} \mathrm{~d} u_{\mathrm{C}}{ }^{\mathrm{B}}=-\frac{4 \pi\left(r^{\mathrm{i}}\right)^{3}}{3 K^{\mathrm{B}}} \mathrm{d} P^{\mathrm{B}},
$$

then

$$
\mathrm{d} u_{\mathrm{C}}{ }^{\mathrm{B}}=-\frac{r^{\mathrm{i}}}{3 K^{\mathrm{B}}} \mathrm{d} P^{\mathrm{B}}
$$

where $K^{\mathrm{B}}$ is the bulk modulus of the brine. 
For the stress-free displacement of the interface viewed from the brine,

$$
V_{\mathrm{T}}^{\mathrm{B}}=\frac{4}{3} \pi\left(r^{\mathrm{i}}\right)^{3}
$$

implies

$$
\mathrm{d} V_{\mathrm{T}}{ }^{\mathrm{B}}=4 \pi\left(r^{\mathrm{i}}\right)^{2} \mathrm{~d} u_{\mathrm{T}}{ }^{\mathrm{B}},
$$

and solving for the differential displacement, we have

$$
\mathrm{d} u_{\mathrm{T}}{ }^{\mathrm{B}}=\frac{\mathrm{d} V_{\mathrm{T}}^{\mathrm{B}}}{4 \pi\left(r^{\mathrm{i}}\right)^{2}} .
$$

This gives us expressions for all of the displacement components.

\section{Pressure model}

To finish the development of the pressure model, we can substitute the expressions for the differential displacements (Equations (32), (34), (37) and (40)) into the compatibility Equation (31), to get

$$
\frac{r^{\mathrm{i}}}{4 \mu^{\mathrm{I}}} \mathrm{d} P^{\mathrm{B}}-\frac{\mathrm{d} V_{\mathrm{T}}^{\mathrm{I}}}{4 \pi\left(r^{\mathrm{i}}\right)^{2}}=-\frac{r^{\mathrm{i}}}{3 K^{\mathrm{B}}} \mathrm{d} P^{\mathrm{B}}+\frac{\mathrm{d} V_{\mathrm{T}}^{\mathrm{B}}}{4 \pi\left(r^{\mathrm{i}}\right)^{2}} .
$$

Combining terms and solving for $\mathrm{d} P^{\mathrm{B}}$,

$$
\mathrm{d} P^{\mathrm{B}}=\left(\frac{3}{4 \mu^{I}}+\frac{1}{K^{\mathrm{B}}}\right)^{-1} \frac{\mathrm{d} V_{\mathrm{T}}^{\mathrm{B}}+\mathrm{d} V_{\mathrm{T}}^{\mathrm{I}}}{V^{\mathrm{i}}} .
$$

Recognizing that $\mathrm{d} V_{\mathrm{T}}^{\mathrm{O}}=\mathrm{d} V_{\mathrm{T}}^{\mathrm{B}}+\mathrm{d} V_{\mathrm{T}}^{\mathrm{I}}$ and that the brine volume $\left(V_{\mathrm{T}}^{\mathrm{B}}\right)$ is a reasonable approximation for the volume enclosed by the interface $\left(V^{\mathrm{i}}\right)$, we can write

$$
\mathrm{d} P^{\mathrm{B}}=\left(\frac{3}{4 \mu^{\mathrm{I}}}+\frac{1}{K^{\mathrm{B}}}\right)^{-1} \frac{\mathrm{d} V_{\mathrm{T}}^{\mathrm{O}}}{V_{\mathrm{T}}^{\mathrm{B}}} .
$$

Integrating,

$$
P^{\mathrm{B}}=\left(\frac{3}{4 \mu^{\mathrm{I}}}+\frac{1}{K^{\mathrm{B}}}\right)^{-1} e_{\mathrm{T}}^{\mathrm{B}}
$$

where the volumetric strain $\left(e_{\mathrm{T}}^{\mathrm{B}}\right)$ was defined previously (Equation (26)). This model seems fairly intuitive. ${ }^{10}$

\section{Example}

To study the behavior of the resulting pressure function, let the bulk modulus of the brine $\left(K^{\mathrm{B}}\right)$ equal $2.0 \mathrm{GPa}$ and let the shear modulus for the ice $\left(\mu^{\mathrm{I}}\right)$ equal $3.6 \mathrm{GPa}$. Then using the volumetric strain function (Equation (26)) with initial temperatures of $T_{\mathrm{o}}=-0.5^{\circ},-1^{\circ},-2^{\circ},-3^{\circ}$ and $-4^{\circ} \mathrm{C}$,

${ }^{10}$ For an upper bound, assume the ice is rigid so that the entire volume change due to the phase transformation must be absorbed by the brine. Using an elastic model, where the brine has a bulk modulus $\left(K^{\mathrm{B}}\right)$, the upper bound for the brine pressure $\left(P_{\mathrm{ub}}{ }^{\mathrm{B}}\right)$ is

$$
P_{\mathrm{ub}}^{\mathrm{B}}=K^{\mathrm{B}} \int_{V_{\mathrm{o}}^{\mathrm{B}}}^{V_{\mathrm{T}}^{\mathrm{B}}} \frac{\mathrm{d} V_{\mathrm{T}}^{\mathrm{O}}}{V_{\mathrm{T}}^{\mathrm{B}}}=K^{\mathrm{B}} e_{\mathrm{T}^{\mathrm{B}}} .
$$

This upper bound corresponds with $\lim _{\mu^{\mathrm{I}} \rightarrow \infty} P^{\mathrm{B}}$, using the definition of $P^{\mathrm{B}}$ in Equation (44). we obtain the pressure profiles shown in Figure 6.

Notice the pressure becomes significant immediately after the brine cell is sealed and begins to cool, particularly for cases with low initial salinity. For the cell model with an initial temperature $T_{\mathrm{o}}=-2^{\circ} \mathrm{C}$, by the time the temperature drops $1^{\circ} \mathrm{C}$ the brine pressure $\left(P^{\mathrm{B}}\right)$ approaches $50 \mathrm{MPa}$, and it reaches a maximum of $285 \mathrm{MPa}$ at the eutectic point $\left(T_{\mathrm{e}}=-21.2^{\circ} \mathrm{C}\right)$.

As we would expect, given the inverse relationship between brine volume and salinity (Relation (11)), the rate of change in the pressure for a change in temperature is dependent on the salinity of the brine. Brine cells which start with a lower initial salinity display a much steeper pressure profile initially, leveling off to display slopes parallel to those which started with a higher initial salinity.

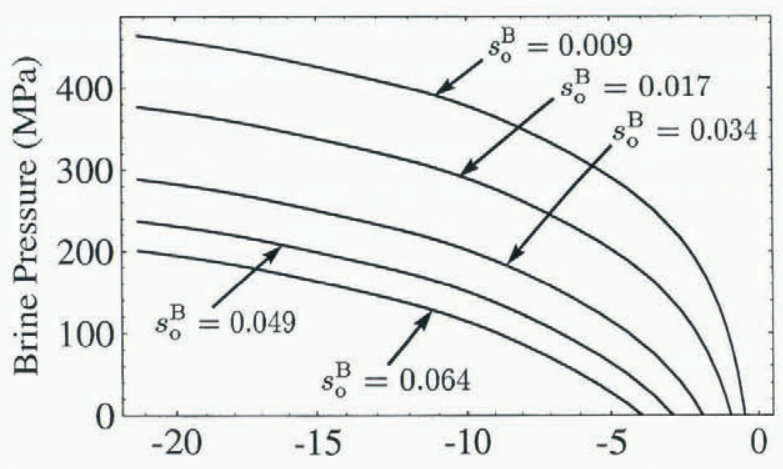

Brine Freezing Temperature $\left({ }^{\circ} \mathrm{C}\right)$

Fig. 6. Brine pressure as a function of salinity.

\section{Discussion}

As can be ascertained, the elastic model would not be valid after inelastic deformation begins and, as we can see (Fig. 6), the pressure modeled at the brine/ice interface approaches the theoretical maximum strength for ice, $\mu^{\mathrm{I}} / 10=360 \mathrm{MPa}$; hence, there is little doubt that the stresses are sufficient to induce inelastic deformation. Though inaccurate for large temperature changes, the model may be useful for estimating the temperature change required to commence yielding as well as the extent of possible yielding.

\section{STRESS VARIATIONS}

Though the pressures in the brine cell can become so large that the elastic model becomes irrelevant, we can still gain some insights into the neighborhood that might be affected by such a pressure build-up.

As a model of the stress distribution in the neighborhood of the brine cell, we will use an elastic model of concentric spheres (Timoshenko and Goodier, 1970, $\S 136)$, and take the limit as the outer radius grows large. Let $R_{\mathrm{i}}$ represent the non-dimensional radius, $r / r^{\mathrm{i}}$, where $r^{\mathrm{i}}$ is the radius to the interface between the brine and the precipitated ice. Using the brine pressure $\left(P^{\mathrm{B}}\right)$ as 
a boundary condition at the interface, the stress components take the following form:

$$
\begin{aligned}
\sigma_{r r} & =-\frac{P^{\mathrm{B}}}{R_{\mathrm{i}}^{3}} ; 1 \leq R_{\mathrm{i}}<\infty \\
\sigma_{t t} & =+\frac{P^{\mathrm{B}}}{2 R_{\mathrm{i}}^{3}} ; 1 \leq R_{\mathrm{i}}<\infty \\
\left(\tau_{x z}\right)_{\max } & =-\frac{3 P^{\mathrm{B}}}{4 R_{\mathrm{i}}^{3}} ; 1 \leq R_{\mathrm{i}}<\infty .
\end{aligned}
$$

In the case of the brine cell, as the pressure accumulates, the radial location of the interface $\left(r^{\mathrm{i}}\right)$ decreases. To approximate the location of the interface relative to the initial position of the interface $\left(r_{\mathrm{o}}{ }^{\mathrm{i}}\right)$, recall the ratio of the brine volume relative to the initial brine volume (Equation (10)), substitute for the volume in terms of the spherical geometry of the brine-cell model $\left(V=4 \pi r^{3} / 3\right)$, and approximate the interface radius $\left(r^{\mathrm{i}}\right)$ by the brine radius $\left(r^{\mathrm{B}}\right)$, to get

$$
\frac{r^{\mathrm{i}}}{r_{\mathrm{o}}{ }^{\mathrm{i}}} \approx \frac{r^{\mathrm{B}}}{r_{\mathrm{o}}{ }^{\mathrm{B}}}=\left[\frac{s_{\mathrm{o}}{ }^{\mathrm{B}}\left(\zeta^{\mathrm{B}}+s_{\mathrm{o}}{ }^{\mathrm{B}}\right)}{s^{\mathrm{B}}\left(\zeta^{\mathrm{B}}+s^{\mathrm{B}}\right)}\right]^{\frac{1}{3}} .
$$

Using this relationship, we can define a new nondimensional radius $\left(R_{0}\right)$ relative to the initial radius:

$$
R_{0}=\frac{r^{\mathrm{i}}}{r_{\mathrm{o}}{ }^{\mathrm{i}}} R_{\mathrm{i}}=\frac{r}{r_{\mathrm{o}}{ }^{\mathrm{i}}} \text {. }
$$

With the preceding information, we can model the elastic stress profiles in the neighborhood of the brine cell due to phase transformations.

\section{Example}

Let the initial interface radius $r_{\mathrm{o}}{ }^{\mathrm{i}}=1$ for an initial temperature $T_{\mathrm{o}}=-2^{\circ} \mathrm{C}$. Then the stress profiles for temperatures $T=-2.5^{\circ},-3^{\circ},-8^{\circ}$ and $-21.2^{\circ} \mathrm{C}$ are shown in Figure 7 with corresponding interface radii $r^{\mathrm{i}}=$ $0.93,0.88,0.64$ and 0.50 .

Notice that the stresses transferred to the region outside of the original brine cell change relatively little as the temperature drops. As the brine pressure increases, the pressure increase is borne by the precipitating ice that generates the pressure increase.

\section{Discussion}

The predominant concern regards the extent of inelastic deformation that might occur in the neighboring ice due to the pressures generated in the brine. As discussed in the previous section, the stresses resulting from our elastic model are well beyond the yield stress for ice. Higashi (1964) shows yield in non-saline single crystals of ice for basal plane shear stresses ranging from 0.06 to $0.44 \mathrm{MPa}$ with strain rates in the range of $0.13-$ $2.7 \times 10^{-6} \mathrm{~s}^{-1}$ and temperatures in the range of $-21^{\circ}$ to $-15^{\circ} \mathrm{C}$. At warmer temperatures and lower rates, where we would expect the phase transformations to have a more significant impact, we would expect yield at even lower stresses.

Comparing this observation with the results in Figure 7, one can conclude that inelastic deformation takes place
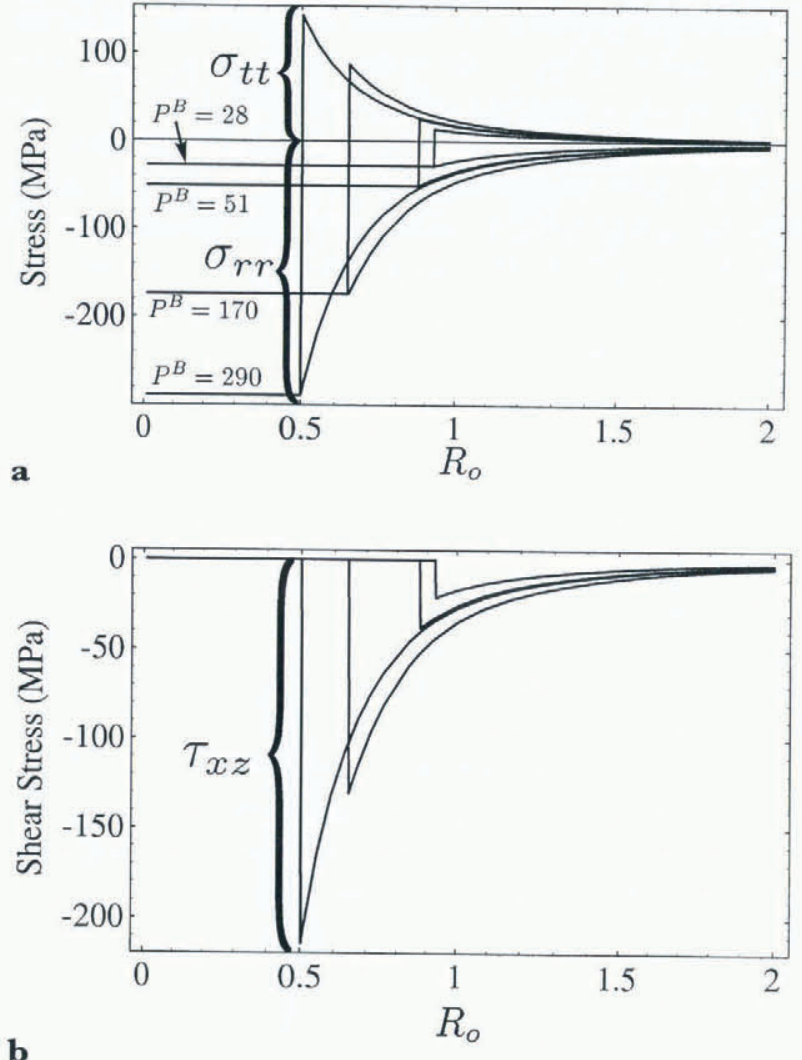

Fig. 7. Stress profiles for the brine cell: (a) principal components, (b) maximum shear.

almost immediately after the brine pocket has sealed off and the temperature begins to drop. Therefore the pressure/ stress curves shown in Figure 7 are unrealistic for saline ice and serve only to show the significance of inelastic deformation that might occur during crystal growth, if the ice surrounding the cell does not fracture immediately.

Wakahama (1967) deduced that for temperatures near $-10^{\circ} \mathrm{C}$, basal slip would occur in ice single crystals for basal plane shear stresses of 0.02-2 MPa. For shear stresses above $2 \mathrm{MPa}$, the ice crystals would fracture. For the sake of argument, assume the shear stress at the interface is near the maximum $\left(\tau_{x z}{ }^{\mathrm{i}}=2 \mathrm{MPa}\right)$ for basal slip. Using the elastic model (Equation (47)), we can estimate brine pressure $\left(P^{\mathrm{B}}=-4 \tau_{x z}{ }^{\mathrm{i}} / 3\right)$, as well as the radial location at which shear stresses have decayed to the minimum "yield" point $\left(\tau_{x z}{ }^{\mathrm{r}}=0.02 \mathrm{MPa}\right)$, i.e.

$$
R_{\mathrm{i}}=\left(\frac{\tau_{x z}{ }^{\mathrm{i}}}{\tau_{x z}{ }^{\mathrm{r}}}\right)^{\frac{1}{3}} \approx 5,
$$

indicating that there is the potential for inelastic deformation at distances up to five times the interface radius $\left(r^{\mathrm{i}}\right)$ away from the brine cell. Because inelastic deformation would occur over the range $\left(r^{\mathrm{i}} \leq r \leq 5 r^{\mathrm{i}}\right)$, this estimate, from our elastic model, of the range of inelastic deformation is only a rough approximation.

\section{ANISOTROPIC FINITE-ELEMENT MODEL}

So far, we have worked with an isotropic model for the ice. Since brine cells will in general be embedded in single 
or quasi-single crystals, we should consider the behavior of our model using anisotropic properties. For this analysis we use a finite-element (FE) model. Also, in the future, we hope to work with a model for brine cavities that is a closer approximation to the expected brine pocket in saline ice, in terms of both geometry and constitutive relations. By comparing our model with the preceding closed-form models, we can validate our FE techniques for future use.

\section{Set-up}

To model the stress field that develops in the ice, we used the ANSYS 5.2 FE model (Swanson Analysis Systems Inc., Houston, Pennsylvania) shown in Figure 8.

Due to the rapid decrease in the stress field near the ice/brine interface (Fig. 7), the shape functions in an FE model will tend to underestimate the stresses at the interface. To determine the accuracy of the FE model, we ran a test case where we applied an internal pressure $\left(P^{\mathrm{B}}=100 \mathrm{MPa}\right)$ and then compared the results with the equilibrium stress relations for concentric spheres (Equations (45)-(47)). We found that with the curved boundaries and somewhat distorted elements, we

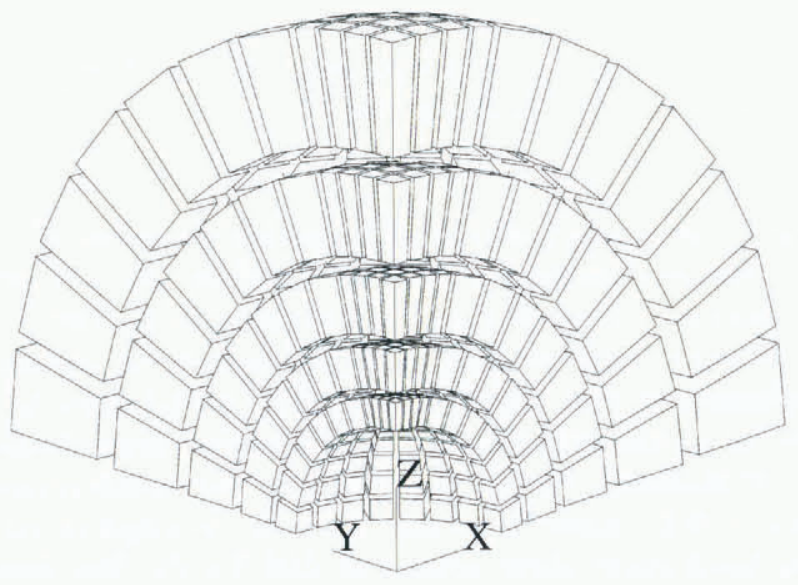

Fig. 8. Inner section of the finite-element model of a spherical ice cell.

achieved better results using elements with quadratic shape functions (i.e. ANSYS, SOLID95). Additionally, to obtain results that were accurate at the inner radius, we had to use a sub-modeling (mesh-refinement) technique. For our coarse model, we started with an outer radius that was 20 times greater than the inner radius. We then used this "coarse" mesh to define displacement boundary conditions for the outer radius of a much finer model where the outer radius was only four times as large as the inner radius. By using this sub-modeling technique, we were able to reduce our maximum discrepancy, which occurred at the interface radius, $r^{\mathrm{i}}$, to less than $3 \%$. If we ran the analysis with only the coarse mesh, the stresses at the inner radius were underestimated by more than $10 \%$.

To model the brine, we filled the spherical vacancy with a second mesh. We used the same element type for both the brine and the ice shell, though we altered the material parameters.
We assumed our model took the "stress-free" configuration at $-2^{\circ} \mathrm{C}$. To model the interference between the brine and ice due to the phase transformations, we used the ice interface as a frame of reference, so that the interference was due to the "apparent" transformation expansion of the brine. To model the "apparent" expansion of the brine in the FE model, we modeled the volumetric strain as a thermal expansion, using the large (logarithmic) strain capabilities of ANSYS. The components of thermal (transformation) strain were represented by

$$
\left(\epsilon_{\mathrm{T}}^{\mathrm{B}}\right)_{\mathrm{i}}=\alpha \Delta T=\frac{e_{\mathrm{T}}^{\mathrm{B}}}{3}
$$

where $\Delta T=T-T_{0}$ is the temperature difference between the initial stress-free temperature $\left(T_{\mathrm{o}}\right)$ and the brine temperature $(T)$, and $\alpha$ is the coefficient of thermal (transformation) expansion, defined in Equation (30).

For the elastic parameters of the brine, we used a bulk modulus of $2 \mathrm{GPa}$ and a Poisson's ratio of 0.498 . For the surrounding ice, we used the coefficient of thermal expansion, $\alpha^{\mathrm{I}} \approx 53 \times 10^{-6}$, as given in Fletcher $(1970)$, though it is negligible relative to the transformation coefficient.

To validate the accuracy of the $\mathrm{FE}$ model relative to the preceding closed-form model, we ran the FE model, for $T=-8^{\circ} \mathrm{C}$, using the following isotropic elastic parameters for the ice (Derradji-Aouat, 1992, table 4.3):

$$
E^{\mathrm{I}}=9.41 \mathrm{GPa} \quad \nu^{\mathrm{I}}=0.308 .
$$

To evaluate the differences in the two isotropic models, we used the radial-stress data from the FE model and applied least-squares fit of the form $-\tilde{P^{\mathrm{B}}} / R_{\mathrm{i}}{ }^{3}$, obtaining $\tilde{P}^{\mathrm{B}}=-170 \mathrm{MPa}$ with a correlation coefficient of 0.9991 and a standard error of $1.02 \mathrm{MPa}$. Comparing this pressure estimate with the pressure estimate from the closed-form model (Equation (44)) yielded a difference of $2.5 \%$, presumably due to the included thermal contraction of the ice and interpolation errors.

To determine the significance of the anisotropic material model relative to the isotropic material model, we used the following orthotropic material parameters,

$$
\begin{aligned}
E_{x}{ }^{\mathrm{I}}=E_{y}{ }^{\mathrm{I}}=\frac{1}{S_{11}}=9.70 \mathrm{GPa} & E_{z}{ }^{\mathrm{I}}=\frac{1}{S_{33}}=11.9 \mathrm{GPa} \\
\nu_{x z}{ }^{\mathrm{I}}=\nu_{y z}{ }^{\mathrm{I}}=-\frac{S_{13}}{S_{33}}=0.223 & \nu_{x y}{ }^{\mathrm{I}}=-\frac{S_{12}}{S_{11}}=0.427 \\
G_{x z}{ }^{\mathrm{I}}=G_{y z}{ }^{\mathrm{I}}=\frac{1}{S_{44}}=3.03 \mathrm{GPa} & G_{x y}{ }^{\mathrm{I}}=\frac{1}{S_{66}}=3.40 \mathrm{GPa} .
\end{aligned}
$$

To obtain the numerical values, we used the polynomial models of Dantl (1968, 1969) for the compliance parameters $\left(S_{i j}\right)$ and evaluated them at a temperature of $-8^{\circ} \mathrm{C}$.

\section{Analysis}

Using the preceding isotropic properties, our FE model produced the tangential $\left(\sigma_{t t}\right)$ and shear $\left(\tau_{x z}\right)$ stress fields shown in Figure 9a and c, respectively. The correspond- 
ing maximum stresses are shown in Table 2. Using the anisotropic properties, our FE model rendered the tangential $\left(\sigma_{t t}\right)$ and shear $\left(\tau_{x z}\right)$ stress fields shown in Figure $9 \mathrm{~b}$ and $\mathrm{d}$, respectively. The corresponding maximum stresses are shown in Table 2.

Table 2. Stress components at the interface

\begin{tabular}{ccc}
\hline & \multicolumn{2}{c}{$\begin{array}{c}\text { Maximum stresses (at the interface) } \\
\text { Stress component } \\
\text { Isotropic model }\end{array}$} \\
$\mathrm{MPa}$ & $\begin{array}{c}\text { Anisotropic model } \\
\mathrm{MPa}\end{array}$ \\
\hline$\sigma_{r r}$ & -164 & -164 \\
$\sigma_{t t}$ & +88.5 & +151 \\
$\tau_{x z}$ & -126 & -114 \\
\hline
\end{tabular}

The stress contours shown in Figure 9c and d represent the magnitude of the shear stress that would result on the basal plane of the ice crystal, if it remained elastic.

Given that most of the anisotropic elastic parameters (Equations (53)) are within $30 \%$ of the isotropic components (Equations (52)), we would expect the stress results to reflect the same order of similarity. The contour plots in Figure 9 demonstrate such a case. The radialstress contour plots displayed so much similarity that they were not deemed worth including.

Consider the stresses in the $x y$ plane. Because the $z$ axis in Figure 9 corresponds with the crystalline $c$ axis, the elastic model is isotropic in the $x y$ (basal) plane. In this plane, the only noticeable difference relative to the isotropic model is that the magnitudes of the radialand tangential-stress components decay slightly slower and faster, respectively, relative to $R_{\mathrm{i}}$.

For stresses along the $z$ axis, the behavior is again very similar to the isotropic case, except the rate of decay in the magnitude of the radial-stress component is significantly slower, yielding a magnitude $100 \%$ greater when $R_{\mathrm{i}}=4$.

Given the magnitude of the stresses predicted, this model is primarily useful for predicting the onset of yielding. Therefore, our primary concern is the magnitude of the shear components that would act on the basal plane. Comparing the shear-stress contour plots (Fig. 9c and d), it is clear that the change in the shear stress field due to anisotropic properties is small. The only notable observation is that in the anisotropic case the shear stress displays a maximum which is about $10 \%$ less, combined with a slightly faster rate of radial decay relative to the isotropic case.

The shear stress contours (Fig. 9c and d) illustrate that basal-plane shear stresses will be significant only at specific points on the surface of the brine-pocket model. These are the points where the basal plane makes a $45^{\circ}$ angle with direction perpendicular to the brine-pocket surface. As a consequence, one would expect to first see dislocations emerging from these preferred regions on the brine-pocket interface.

\section{Discussion}

In summary, based on comparisons between models with isotropic and anisotropic material parameters for single

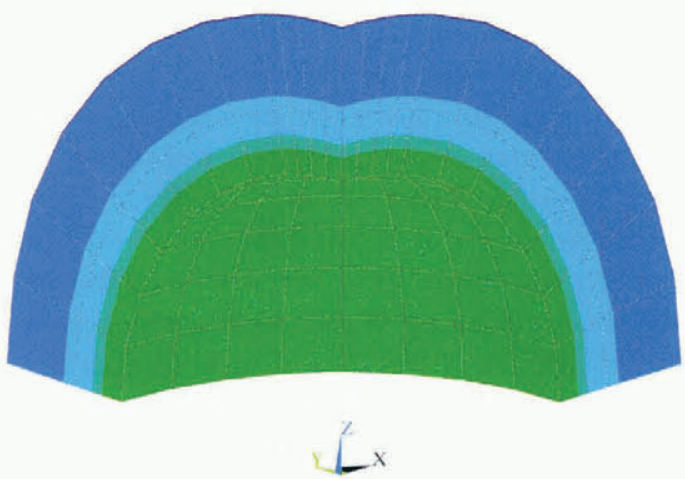

$\mathbf{a}$

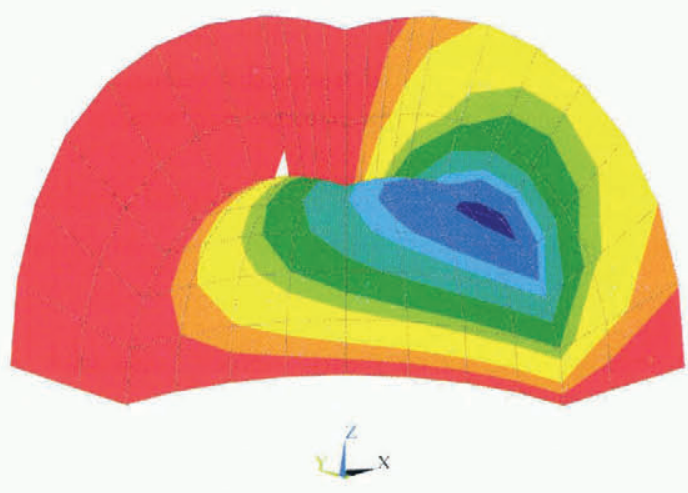

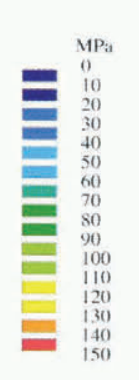

b
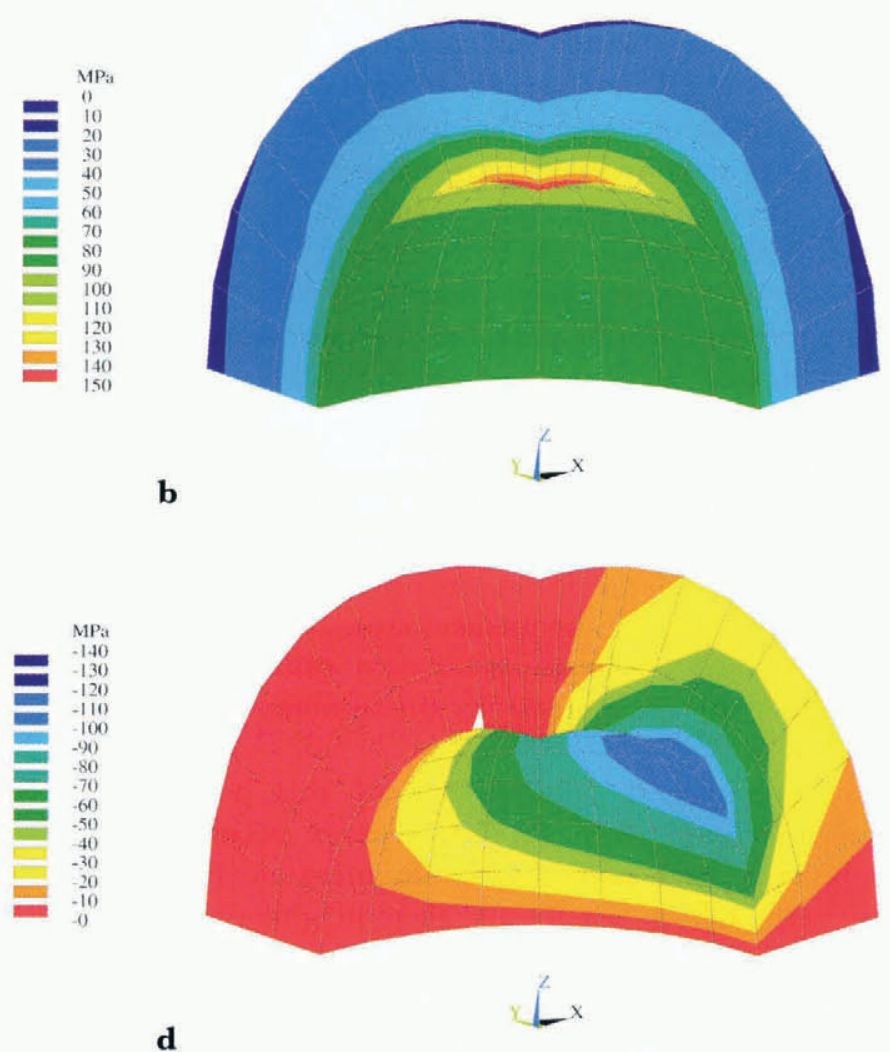

Fig. 9. Stress contours $\left(T=-8^{\circ} C\right):$ (a) $\sigma_{t t}$ contours (isotropic model); (b) $\sigma_{t t}$ contours (anisotropic model); (c) $\tau_{x z}$ contours (isotropic model); (d) $\tau_{x z}$ contours (anisotropic model). 
crystals of ice, the isotropic elastic model yields approximations that are very reasonable relative to the anisotropic case. In particular, the isotropic model works quite well for predicting the onset of yield, though it may be a bit conservative.

\section{DISCUSSION AND CONGLUSIONS}

Given the nature of the rapid stress increases predicted here, in the most general case, the pressures generated by transformations will simply crack/destroy cell walls at their weakest point, providing a mechanism for "brine expulsion" (Knight, 1962; Bennington, 1963; Cox and Weeks, 1975) and, hence, stress relief. For this expansion mechanism to play a significant role in inelastic predeformation of the ice matrix, the brine must be constrained from "flushing". In sea ice, Bennington points out, when the circulation of brine is restricted, deformation bands develop in the ice. These bands, which he refers to as corrosion bands, always occurred $3-6 \mathrm{~cm}$ above the ice/water interface, and are most likely symptoms of "brine expulsion".

It seems plausible that the same phenomena can occur throughout the ice matrix with a less dramatic display. Once the initial brine drainage has taken place, many of the remaining brine cells will be rather isolated. Others will migrate though the ice matrix into isolated regions. In their isolation, they can develop a wall thickness sufficient to prevent expulsion. If these isolated brine cells are then cooled, either the stresses generated will introduce microcracks into which the brine can flow, or the neighboring ice can deform through inelastic mechanisms. Given the time-dependent nature of dislocation motion, if the pressure accumulates too rapidly, microcracking will occur. If the pressure accumulates slowly enough, dislocation mechanisms will provide a mode of stress relaxation. In the process, the mobile dislocation density will increase.

This phase-transformation mechanism (water to ice) can be used to explain the nucleation of dislocations in non-saline ice. For example, Oguro and Higashi (1981) use this mechanism to explain the existence of interstitial dislocation loops in non-saline single crystals of ice. For non-saline ice, the rate of stress increase is a function of the heat flux rather than the temperature change.

Suppose a saline ice crystal undergoes a temperature change. If the temperature drops rapidly, some of the brine will freeze, large interference strains will develop, and microcracking will be predominant. If a temperature change is "small", dislocations will have sufficient time to act, leading to an increase in the mobile dislocation density.

As experimental confirmation of this possibility, consider pictures taken through crossed polarizers by both Knight (1962, plate 3A) and Bennington (1963, fig. 17) of brine cells in sea ice and their neighboring strain (dislocation) shadows. These strain shadows developed in the high basal-plane shear stress regions corresponding to internal stresses generated by phase transformations (see Fig. 9c and d). Knight continues to show, after a period of time, the redistribution of generated dislocations into polygonized crystal sub-boundaries.
For a better understanding of the geometrical significance of this dislocation nucleation mechanism, consider the geometry of the ice matrix. For the spatial distribution of brine cells in sea ice, Anderson and Weeks (1958) recorded initial cell diameters of about $0.07 \mathrm{~mm}$ with platelet thicknesses of about $0.46 \mathrm{~mm}$ and a diametral spacing between brine cells in the brine layer of about $0.23 \mathrm{~mm}$. Kingery and Goodnow (1963) recorded brine-cell migration velocities of up to $0.02 \mathrm{~mm} \mathrm{~h}^{-1}$.

Given the relative spacing between brine cells, it is possible that a significant part of the ice matrix yields with each small temperature decrease. If there is a temperature gradient, the brine cells will migrate and another temperature decrease will produce yield in a different part of the ice matrix. Given this scenario, it is not unreasonable to assume that the increase in the mobile dislocation density and subsequent redistribution can result in a significant change in the mechanical properties of saline ice. In addition, it seems quite plausible that a steady-state mobile dislocation density can be obtained without the application of an external stress.

\section{Gas inclusions}

Notice our model does not include the effects of gas that will be coincidentally trapped along with the brine. When the brine is sealed in a cell, it will contain a certain amount of dissolved gas. As ice precipitates from the brine, the gas and salt in the brine will remain relatively constant. Hence, the remaining brine will become increasingly saturated with gas. At the same time, the remaining brine will become increasingly salty, and increasing brine salinity results in decreasing gas solubility in the brine, sometimes referred to as "saltingout". ${ }^{11}$ To counter these two factors, both the brinepressure increase and the temperature decrease which occur coincidentally with the reduction in brine volume will increase the gas solubility. In the situation modeled, the dissolved gas may never nucleate a bubble.

Whether a bubble forms or not, consider the amount of gas that might coexist in a brine cell. As a rough upper bound for the dissolved gas, we will use the closest solubility data provided by Weiss (1970), which is for sea water with a salinity of 0.035 and at a temperature of $-1^{\circ} \mathrm{C}$. In this case, the sum of the solubilities of $\mathrm{N}_{2}, \mathrm{O}_{2}$, and $\mathrm{Ar}$ yields a gas solubility of 0.02326 ( 1 of gas)/(1 of brine); so, up to $2.3 \%$ of the original cell volume might be occupied by dissolved gas. At the same time, it is possible that a bubble will float up from below and enter the cell before it is sealed off. In summary, the volume occupied by gas in a brine cell is likely to vary anywhere between $1 \%$ and $100 \%$.

The more gas there is in the cell, whether dissolved or in bubble form, the less brine there is available to

\footnotetext{
"To illustrate the "salting-out" effect, consider data provided by Weiss $(1970)$. For distilled water at $0^{\circ} \mathrm{C}$ the sum of the solubilities of $\mathrm{N}_{2}, \mathrm{O}_{2}$ and $\mathrm{Ar}$ is 0.02914 ( $\mathrm{l}$ of gas $) /(1$ of brine). Compare this with sea water at a temperature of $0^{\circ} \mathrm{C}$ and a salinity of 0.035 , for which the summed solubility of the same components is 0.02235 ( 1 of gas)/( 1 of brine).
} 
transform to ice, and, therefore, the less the cell contents will expand relative to their initial size. Coincidentally, the gas in the cell will compress much more readily, so that the pressure generated will be significantly reduced. As a lower bound, a cell filled completely with gas will generate virtually no internal stress; our model gives an upper bound for brine cells containing gas.

The role that bubbles play in the transformation process is also dependent on the directional nature of the freezing process. Nakaya (1956, plate 44), in his study of internal melt figures, demonstrated that typically when freezing is "isotropic", the vapor bubble will shrink in size as the water/ice transformation progresses. In the case of bubbles generated by internal melt, the bubble will eventually vanish. If the freezing process is "orthotropic", in particular if the rate of freezing is faster from the top down, the buoyancy of a bubble will typically result in its isolation as the precipitating ice freezes around it (Nakaya, 1956, plates 45-47). Once a bubble has been isolated, the model proposed in this paper provides an approximation for the strain and pressure build-up, though with altered initial conditions.

\section{Relevance to sea ice}

As Cox and Weeks (1975) point out, the phase transformations for brine in sea ice and saline ice are similar at temperatures above $-8.2^{\circ} \mathrm{C}$. At temperatures below $-8.2^{\circ} \mathrm{C}$, solid salts begin to precipitate out of the brine in sea ice and, according to Peyton (1966, §6.2.2), merge with the precipitating ice to form an inner shell of "salty" ice. For uniaxial specimens, Peyton found that the solid salts did not significantly alter the tensile behavior but had a stiffening effect on the compressive behavior. Most likely the solid salts will have a reinforcing effect on the precipitated "salty" ice shell. We have not included any solid-salt effects, so our model will lack accuracy for temperatures below $-8.2^{\circ} \mathrm{C}$; however, we feel our model is accurate for sea ice at temperatures above $-8.2^{\circ} \mathrm{C}$. Of course, as in saline ice, the strain measures are relevant for all temperatures down to the eutectic point, while the pressure/stress measures developed in this paper are relevant only in the elastic range.

Natural sea ice does not normally experience rapid temperature changes. The bottom of an ice sheet is always at temperatures near the melting point, even though the top surfaces may experience temperatures as low as $-50^{\circ} \mathrm{C}$, particularly near the Antarctic coast. In this fashion, the heat capacity of the underlying sea water serves as a temperature moderator for the ice sheet above. With moderated temperature changes, less than $1^{\circ} \mathrm{C}$, dislocations are likely to nucleate, indicating that the processes modeled here are quite relevant to typical seaice sheets in the polar regions.

\section{SUMMARY}

Much of what is discussed in this paper is physically significant for an understanding of the mechanical behavior of saline $(\mathrm{NaCl})$ ice, as well as sea ice, in that we addressed the physical processes responsible for its unique mechanical properties.
In particular, we addressed the problem of whether or not phase transformations in brine cells can be responsible for the generation of dislocations. We determined that the stresses that would be reached due to freezing of water from brine in these pockets can, due to expansion, produce stresses of sufficient magnitude to nucleate dislocations. Using an elastic model, we were unable to determine exactly what stress levels would be reached; rather, we were able to demonstrate that stresses can be reached that will nucleate dislocations. These results are in agreement with experimental observations of strain figures near brine cells.

Once dislocations begin to nucleate, stress relaxation occurs; as freezing continues, inelastic deformation continues. Eventually, a quasi-equilibrium balance between expansion and relaxation processes may be reached, rendering stresses substantially lower than those calculated here. This balance, of course, depends on the rate of cooling, the cooling patterns and, in general, the temperature history of the total brine/ice system.

The changes in mobile dislocation densities resulting from varied temperature histories, and hence varied brine-cell histories, can result in significant variations in the mechanical behavior of saline (sea) ice.

\section{ACKNOWLEDGEMENTS}

The work presented here was done under the sponsorship of the U.S. National Science Foundation, grant No. CMS-9312621. The authors wish to express their appreciation for NSF's support.

The first author would like to thank H. Frost and D. Cole for an insightful discussion on brine-cell expansion. In addition, we extend thanks to the reviewers for their helpful suggestions.

\section{REFERENCES}

Anderson, D. L. 1958. A model for determining sea ice properties, In Arctic sea ice. Conference held at Easton, Maryland, February 24-27, 1958. Washington, DC, U.S. National Academy of Sciences, 148-156. (National Research Council Publication 598.)

Anderson, D. L. and W. F. Weeks. 1958. A theoretical analysis of sea-ice strength. Trans. Am. Geophys. Union, 39 4), 632-640.

Assur, A. 1958. Composition of sea ice and its tensile strength. In Arctic sea ice. Conference held at Easton, Maryland, February 24 27, 1958. Washington, DC, U.S. National Academy of Sciences, 106-138. (National Research Council Publication 598. )

Atkinson, K. E. 1989. An introduction to mumerical analysis. Second edition. New York, Wiley.

Bennington, K. O. 1963. Some crystal growth features of sea ice. $\mathcal{F}$. Glaciol., 4 (36), 669-688.

Brown, R. L. and T. Kawamura. 1991. A preliminary comparison of the properties of pure ice and sea ice single crystals. Cold Reg. Sci. Technol., $19(3), 275-284$.

Cox, G. F. N. and W. F. Weeks. 1975. Brine drainage and initial salt entrapment in sodium chloride ice. CRREL Res. Rep. 345.

Cox, G. F. N. and W. F. Weeks. 1983. Equations for determining the gas and brine volumes in sea-ice samples. J. Glaciol., 29 102), 306-316.

Dantl, G. 1968. Die elastischen Moduln von Eis-Einkristallen. Phys. Kondens. Mater., 7 (5), 390-397.

Dantl, G. 1969. Elastic moduli of ice. In Riehl, N., B. Bullemer and H. Engelhardt, eds. Physics of ice. New York, Plenum Publishing Corp., $223-230$.

Derradji-Aouat, A. 1992. Mathematical modelling of monotonic and cyclic behaviour of polycrystalline fresh water ice. Ph.D. thesis, University of Ottawa.) 
Fletcher, N. H. 1970. The chemical physics of ice. Cambridge, Cambridge University Press.

Grenfell, T. C. 1983. A theoretical model of the optical properties of sea ice in the visible and near infrared. J. Geophys. Res., 88(C14), 9723-9735.

Johnston, W. G. and J.J. Gilman. 1960. Dislocation multiplication in lithium fluoride crystals. J. Appl. Phys., 31(4), 632-643.

Kawamura, T. 1986. A method for growing large single crystals of sea ice. 7. Glaciol., 32(111), 302-303.

Kingery, W. D. and W. H. Goodnow. 1963. Brine migration in salt ice. In Kingery, W. D., ed. Ice and snow: properties, processes, and applications. Cambridge, MA, M.I.T. Press, 237-247.

Knight, C.A. 1962. Polygonization of aged sea ice. 7. Geol., 70 (2), 240-246.

LaChapelle, E. 1968. Stress-generated ice crystals in a nearly isothermal two-phase system. J. Glaciol., 7 (50), 183-198.

Love, A. E. H. 1944. A treatise on the mathematical theory of elasticity. New York, Dover.

Michel, B. 1978. Ice mechanics. Québec, Qué., Presses de L'Université Laval.

Nakaya, U. 1956. Properties of single crystals of ice, revealed by internal melting. SIPRE Res. Pap. 13.

Oguro, M. and A. Higashi. 1981. The formation mechanism of concentric dislocation loops in ice single crystals grown from the melt. 7. Cryst. Growth, 51, 71-80.

Peyton, H. R. 1966. Sea ice strength. College, AK, University of Alaska. Geophysical Institute. (Technical Report UAG-R-182.)

Picu, R.C., V. Gupta and H.J. Frost. 1994. Crack nucleation mechanism in saline ice. 7. Geophys. Res., 99(B6), 11,775-11,786.

Pounder, E. R. 1965. Physics of ice. Oxford, Pergamon Press.

Savitzky, A. and M.J. E. Golay. 1964. Smoothing and differentiation of data by simplified least squares procedures. Anal. Chem., 36, 16281639.

Timoshenko, S. P. and J. N. Goodier. 1970. Theory of elasticity. Third edition. Tokyo, McGraw-Hill.

Wakahama, G. 1967. On the plastic deformation of single crystal of ice. In Ôura, H., ed. Physics of snow and ice. Vol. 1, Part 1. Sapporo, Hokkaido University. Institute of Low Temperature Science, 291-311.

Weeks, W.F. and S.F. Ackley. 1982. The growth, structure, and properties of sea ice. CRREL Monogr. 82-1.

Weeks, W. F. and A. Assur. 1967. The mechanical properties of sea ice. CRREL Monogr. II-C3.

Weiss, R.F. 1970. The solubility of nitrogen, oxygen and argon in water and seawater. Deep-Sea Res., 17(4), 721-735.

Winegard, W. C. 1964. An introduction to the solidification of metals. London, Institute of Metals.

MS received 22 May 1995 and accepted in revised form 5 June 1996 